
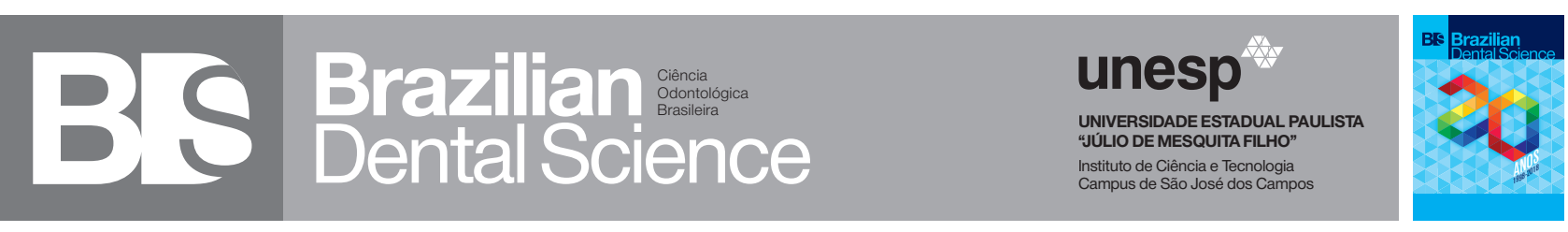

\title{
Minimally invasive approach to diastema closure using lithium disilicate porcelain veneers: clinical report
}

Abordagem minimamente invasiva para fechamento de diastema usando laminados cerâmicos de dissilicato de lítio: relato clínico

Sofia Chane BUZETTO ${ }^{1}$, Priscila Regis PEDREIRA ${ }^{1}$, Janaina Emanuela DAMASCENO ${ }^{1}$, Josué Junior Araujo PIEROTE ${ }^{1}$, Giselle Maria MARCHI $^{1}$, Luis Alexandre Maffei Sartini PAULILLO ${ }^{1}$

1 - Department of Restorative Dentistry - Piracicaba Dental School - State University of Campinas - Piracicaba - SP - Brazil.

\begin{abstract}
Objective: Numerous advances in dentistry techniques and material have allowed patients to have not only a functional but also an aesthetic smile in a conservative way. This case report describes a treatment with ceramic laminates to solve the aesthetic problems of an 18-year-old male dissatisfied with his smile. Following the correct protocols, using minimally invasive abrasions, ceramic laminates, and strong adhesion between porcelain and dental enamel can provide predictable results and clinical longevity through follow-up.
\end{abstract}

\section{KEYWORDS}

Dental veneers; Ceramic; Dental materials.

\section{RESUMO}

Objetivo: Devido aos inúmeros avanços das técnicas e materiais odontológicos tem sido possível proporcionar ao paciente não só a função, mas também a estética do sorriso de maneira minimamente invasiva. Esse relato de caso descreve o tratamento com laminados cerâmicos para resolver problemas de um paciente de 18 anos gênero masculino insatisfeito com o seu sorriso. Seguindo os protocolos corretamente, utilizando desgastes minimamente invasivos, laminados cerâmicos, e forte adesão entre a porcelana e o esmalte dental, é possível obter resultados previsíveis e longevidade clínica mediante acompanhamento.

\section{PALAVRAS-CHAVE}

Facetas dentárias; Cerâmica; Materiais dentários.

\section{INTRODUCTION}

$\mathrm{N}$ owadays, people are increasingly concerned with aesthetic aspects, and, the smile has a very important role in achieving that ideal appearance. Therefore, the demand for aesthetic dental treatments has increased, as much for the reestablishment of function and health as for oral aesthetics $[1,2]$. The number of young patients seeking conservative procedures in dental offices with the use of adhesive materials to preserve dental structure is growing [1,2-4].

A very common problem that affects adults is diastema. Diastemata are spaces between the teeth, which can be of various sizes and between any teeth. They can occur for several reasons, including normal physiological events, genetic and racial predisposition, growth failure, tooth size discrepancies, inadequate dental angulations, pathologic conditions, and even iatrogenic results of orthodontic procedures, such as rapid expansion $[5,6]$. When reaching anterior teeth, they are usually noticed by patients because they are in an aesthetical region. Correct diagnosis and a multidisciplinary approach are necessary to achieve a satisfactory final aesthetic outcome for diastema treatment $[1,5]$.

To correct the shape of the anterior teeth there are three basic treatment options: the addition of composite resin, indirect ceramic restorations, and metal-free crowns (lithium disilicate, zirconia, feldspathic ceramics, and alumina)[7]. Therefore, this work aimed to 
present a minimally invasive approach to reestablish smile aesthetics using lithium disilicate porcelain veneers as an alternative.

\section{CASE REPORT}

An 18-year-old male patient was not satisfied with his facial aesthetics. He wished to have a smile that was compatible with his profile and height. Clinical and radiographic analyses revealed diastema between the central incisors, small vestibularization, correct occlusion, and satisfactory oral hygiene (Figure $1 \mathrm{~A}-\mathrm{C}$ ). After all the treatment options were discussed, the decision was made to prepare the six upper anterior teeth for lithium disilicate ceramic veneers for aesthetic reestablishment. The patient opted for ceramic laminate treatment due to the durability of the material in the long term, despite minimal wear of the tooth structure.
After patient approval of the treatment plan, an office dental bleaching session with three applications of 15 minutes each was performed using a 35\% hydrogen peroxide gel, (Whiteness HP MAXX, FGM Products, Santa Catarina, Brazil) and a satisfactory color was achieved. An impression was made using an alginate material (Hidrogum, Zermack, Labordental, São Paulo, Brazil) for the reproduction of plaster models. Additionally, the plaster models were sent to a dental laboratory, and a diagnostic wax-up was done, which assists in making the mockup (Figure 1D-F). This procedure allows both the dentist and the patient to see and evaluate what the result of the procedure will be before beginning tooth preparation. Tooth color evaluation was performed using a VITA scale, and the shade B1 was selected (Figure 2).

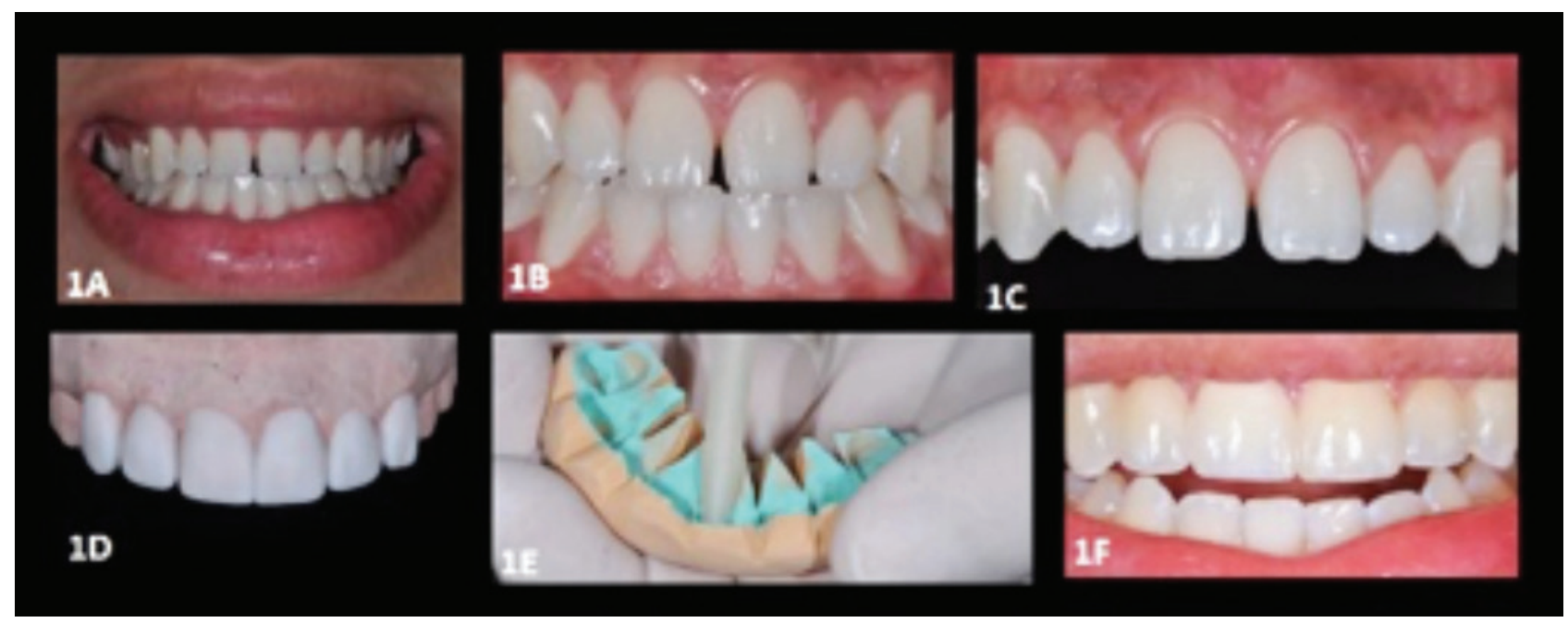

Figure 1A-F - Pretreatment aspect, close-up smile views (A), intraoral view of maximum intercuspation (B), and visualization of the isolated upper $\operatorname{arch}(\mathrm{C})$. Diagnostic wax-up (D). Diagnostic mock-up (E-F).

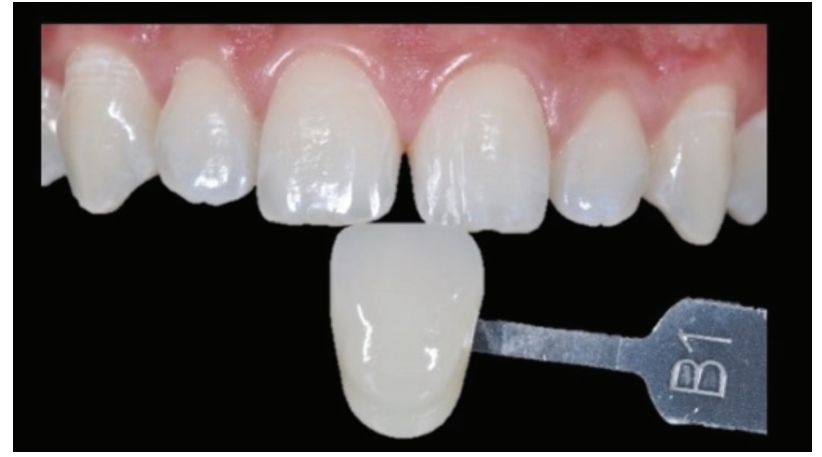

Figure 2 - Tooth color evaluation.
From the waxing, two molds were obtained. The first was used in addition to silicone (Elite HD +, Zhermack, Labordental, São Paulo, Brazil) to make the mock-up with bis-acrylic resin (Structur 3, Voco do Brasil, Porto Alegre, RS). The second, in condensation silicone (Profile, Coltene Vigodent, Rio de Janeiro, Brazil) was used as a guide for tooth preparation (Figure 3A).

Minimally invasive reductions were made, always guided by the silicone model. With a 4138 extra-fine diamond drill (KG Sorensen, 
São Paulo, Brazil), the vestibularized central incisor angles were smoothed (Figure 3B) to allow the insertion of axis laminates without any retention. The remaining preparation, after positioning the silicone model, was done with abrasive disks (Kerr Dental, São Paulo, Brazil) of various granulations from pen marks (Figure 3C and 3D) to identify the exact regions that showed reduction need. This step guarantees safety at the time of tooth preparation, ensuring that the reductions are limited to the enamel, where the adhesion between tooth, cement, and veneer is excellent. Because the patient already had diastema, only a strip of metallic sandpaper and the abrasive discs (Kerr Dental) were needed to guarantee the insertion of the veneers. The last stage of this process was dental polishing with a silicon carbide brush (Jiffy Brush, Ultradent Products, São Paulo, Brazil), as well as finegrained abrasive discs (Kerr Dental).

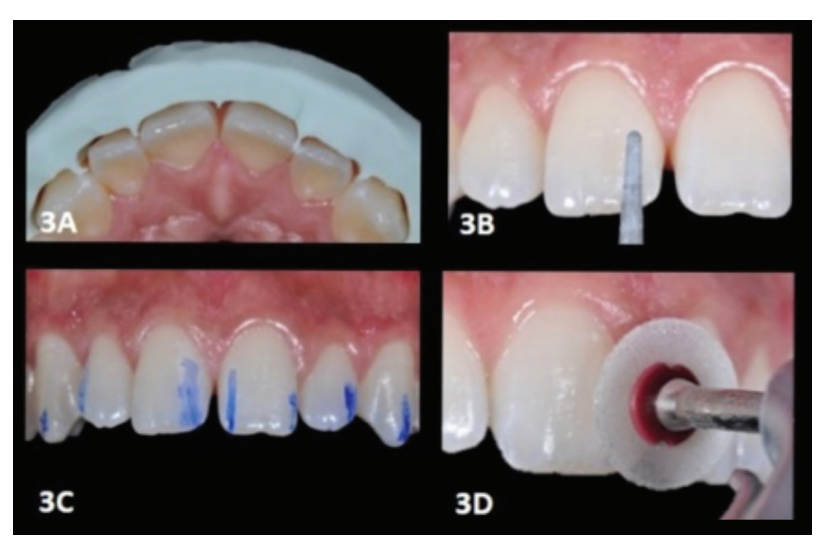

Figure 3A-D - Guide to tooth preparation (A). Smoothness of the central incisor angles (B). Marking with pen (C) and reduction of areas with abrasive disks (D).

Two retraction cables (Ultrapack, Ultradent Products, São Paulo, Brazil) were placed in the gingival sulcus only by the vestibular portion. The first cable was of smaller diameter (000) and the second of larger diameter (00) to guarantee the accuracy of the cervical region at the time of impression. With additional silicone, the impression was obtained shortly after the removal of the two cables, with the light and heavy material at the same time, to obtain a final plaster model.

Once the veneers were received from the technician, the gingival aspect was checked to evaluate the absence of inflammation and bleeding. The veneers were measured with a crown gauge, and some veneer portions were made with 0.2 $\mathrm{mm}$. For this reason, the handling of the veneers had to be done with great caution, because, while not cemented in a tooth, the ceramic could be easily fractured, and all the above steps would have to be redone. The strength of the ceramic is only increased when there is contact between tooth, cement, and ceramic, after cement photoactivation.

A dry test of the laminates was performed with care to place the veneers and avoid any type of fracture. Afterward, try-in pastes were tested in different cement (RelyX Venner, 3M ESPE) shades (A1, WO, and translucent), and the most satisfactory was the WO color.

A modified rubber dam isolate was done to start the cementation step. The veneers were treated with 9.5\% hydrofluoric acid (Condac Porcelana, FGM Products) for one minute (Figure 4A) in the inner portion, which would come into contact with the cement. After that, they were washed abundantly in a water stream and air dried (Figure 4B). Then, two layers of two-step silane (Dentsply Sirona, Rio de Janeiro, Brazil) were applied (Figure 4C), and finally, the Relyx Veneer B1 resin cement (3M ESPE, São Paulo, Brazil) was applied to the inner surface of the veneer. While in the teeth, $37 \%$ phosphoric acid (Prosil, FGM Products) was applied for 30 seconds (Figure 4D and 4E), because it was only enamel, washed with water, and dried (Figure 4F and 4G). After that, the tooth was submitted to a one-step adhesive system (Single Bond, 3M ESPE) (Figure 4H and $4 \mathrm{I}$ ) and a light air jet was applied to the surface and then photopolymerized for 40 seconds. Each of these steps was done tooth by tooth.

The veneer with the cement was positioned with an adapted micro brush. After being positioned, photoactivation of 5 seconds was conducted to ensure that the excesses were carefully manually removed. After that, a final 40 second photoactivation was performed on each face, buccal and palatal, of each of the six elements. When all the pieces were positioned and cemented, the cervical margins were checked, and adjustments were performed with extra-fine diamond drills (KG Sorensen). The final polishing was done with ceramic polishing drills (Exa Cerapol, Edenta) in several shapes and three different granulations in decreasing grains. After the occlusion adjustments, the final result could be seen immediately (Figure 5A). After 7 days, final aesthetics were evaluated, and treatment success was confirmed (Figure 5B and 5C). 


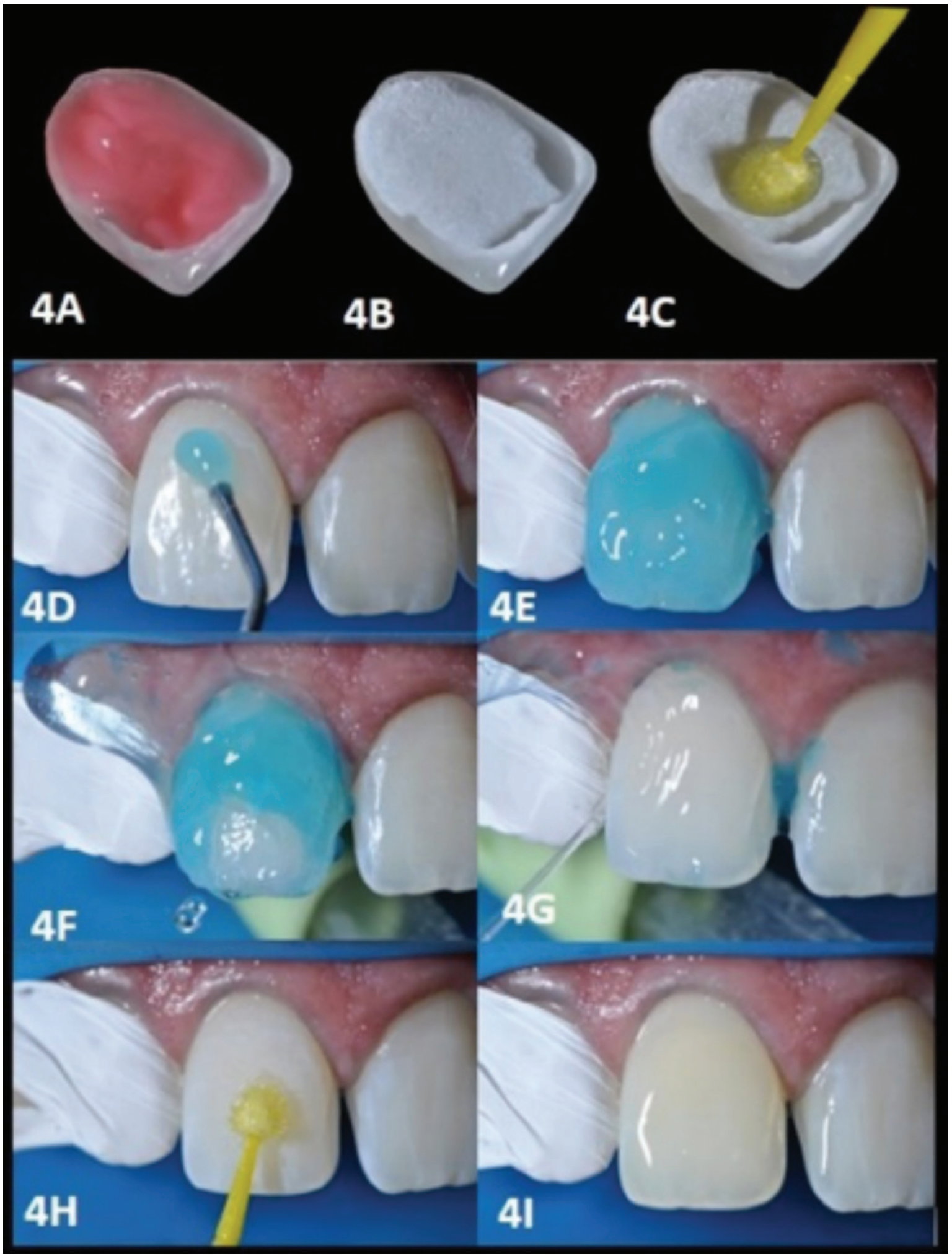

Figure 4A-I - Conditioning of the internal surface of the ceramic veneer with application of hydrofluoric acid (A), aspect of the ceramic veneer after etching (B) and application of silane ceramic primer (C). Conditioning of the tooth with application of phosphoric acid (D and E), washing the surface to remove acidic conditioning ( $F$ and $G$ ) and application of the adhesive system ( $\mathrm{H}$ and $\mathrm{I})$. 


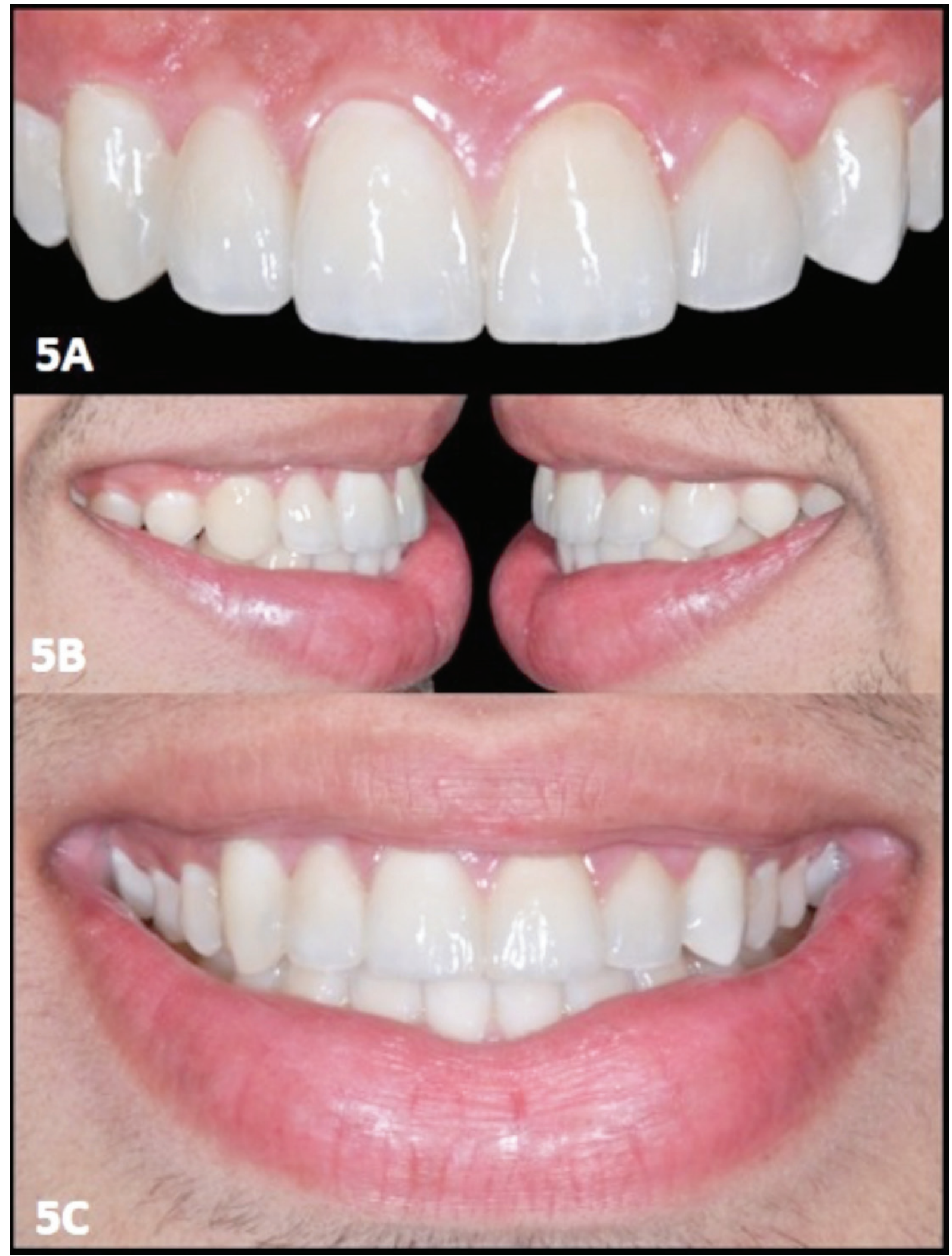

Figure 5A-C - Final aspect immediately after the cementation of the veneers (A) and final aspect of the clinical follow-up after 7 days (B and C). 


\section{DISCUSSION}

In this case report, the patient was dissatisfied with the morphology of his anterior teeth, which were rounded to a masculine smile and had diastema between the central incisors.

Some criteria should be considered when choosing between direct and indirect restorations. We must ensure minimum dental structure reduction, preserve dental vitality, analyze aesthetic demand, ensure no invasion of the gingival complex, and take into account the age of the patient, the cost, and the time of each treatment.[1,2-4]

Indirect restorations have excellent biocompatibility and are most similar to the normal tooth appearance, in shape, color, and brightness, because they have excellent optical characteristics when compared to direct restorations. Color stability is not guaranteed in resins as much as in ceramics, and resins are more susceptible to fractures.[8-10] However, some contraindications should be taken into account for the use of ceramics: bruxism to a severe degree, decreased interocclusal distance, parafunctional activities, overjet, and greatly increased overbite. Additionally, the success of indirect restorations depends directly on a suitable sequence of steps, which include a correct treatment plan, and choosing the type of ceramic indicated for the specific case and technique, especially in the tooth preparation and cementation of the ceramics.[9-11]

Ceramic laminates have gained considerable importance with the increase of aesthetic demand and often offer a treatment option with minimal preparation of dental structure. However, the prevention of micro infiltrations is a very important factor for the longevity of the restoration. An in vitro study by Celik et al.[12] showed that preparation and polymerization techniques have demonstrated different effects on microleakage in ceramic laminates. Restorations that involve problems in sealing margins can allow for bacterial penetration and as a result may cause marginal staining, postoperative sensitivity, and recurrent caries.[12]
Considering the various factors involved in the longevity of ceramics, studies have shown that patients who have good hygiene and yearly followup have an excellent rate of indirect restoration permanence. According to Olley et al.[13], in a follow-up of 50 years of clinical cases, the survival rate of indirect restorations in anterior teeth made in feldspathic ceramics is better than in posterior teeth (95\%). Both feldspathic ceramics and glassinfiltrated ceramics have similar survival rates of $96 \%$ to $98 \%$ when evaluated at 5 years. When compared to other materials (for example, use of the technique in direct composite resin), the success rate of the ceramics was higher (94\%) than of the lower composite resin (74\%). [13]

It is noteworthy that the possibilities of treatment with composite resin or ceramic laminates, as well as their advantages and limitations, were evaluated together with the patient. In this case, the ceramic laminates were made of lithium disilicate because most thin ceramic laminates are made of this material. This material, compared to others (for example, leucite-enhanced ceramics), has higher biaxial strength and fracture resistance.[11] Despite the minimally invasive approach of composite resin, this type of restoration would suffer from limited longevity because the material remains susceptible to discoloration, wear and marginal fractures, which would reduce the success of the aesthetic result in the long term.[8] Therefore, ceramic laminates were proposed as restorations for this treatment due to their durability, in addition to superior aesthetics. [11] This type of restoration can be implemented using strictly enamel sintering ceramics on a dentinal core-type framework (cut-back technique) only where little space is available.[7,13] The complete crystallization of lithium metasilicate is achieved during burning and is associated with the final strength of the ceramics. $[14,15]$

To ensure minimally invasive dentistry requires a complete understanding of smile aesthetics and function. All clinicians, as well as the patient, were involved in the decision-making process and followed the steps correctly, which made it possible to achieve an aesthetic result by ensuring the minimum dental structure was removed. $[1-3,16]$ 


\section{CONCLUSION}

The use of ceramic laminates is recommended in cases where the tooth presents inadequate morphology and coloration. Although it presents some disadvantages, this treatment offers advantages such as a perfect bond between tooth and ceramics, minimal wear, and, due to the properties of the ceramics, a satisfactory aesthetic result.

\section{REFERENCES}

1. Alberton SB, Alberton V, de Carvalho RV. Providing a harmonious smile with laminate veneers for a patient with peg-shaped lateral incisors. JConserv Dent. 2017 May-Jun;20(3):210-3. doi:10.4103/0972-0707.218311.

2. Nakamura M, Matsumura $\mathrm{H}$. The 24-year clinical performance of porcelain laminate veneer restorations bonded with a two-liquid silane primer and a tri-n-butylborane-initiated adhesive resin. J Oral Sci. 2014 Sep;56(3):227-30.

3. Frascaria M, Casinelli M, Mauro S, MD'Amario M, Gatto R, Marzo G. Aesthetic rehabilitation in a young patient using a minimally invasive approach. $A$ multidisciplinary case report. Eur J Paediatr Dent. 2016 Sep;17(3):234-8.

4. Liebermann A, Edelhoff D, Prandtner 0, Saeidi Pour R. Minimally invasive treatment of an ankylosed, severely discolored, and intruded central incisor with a masking ceramic veneer: A clinical report. Int J Periodontics Restorative Dent. 2018 Jan/Feb;38(1):121-6. doi: 10.11607/prd.2874.

5. Naorungroj S. Esthetic reconstruction of diastema with adhesive tooth-colored restorations and hyaluronic acid fillers. Case Rep Dent. 2017;2017:5670582. doi: 10.1155/2017/5670582. Epub2017 Mar 12.

6. MBapatS, Singh C,Bandejiya P.Closing a large maxillary median diastema using bapat power arm. Int JClin Pediatr Dent. 2017 Apr-Jun;10(2):201-4. doi: 10.5005/jp-journals-10005-1435. Epub 2017 Jun1.
7. Edelhoff D, Prandtner 0, Saeidi Pour R, Liebermann A, Stimmelmayr M, Güth JF. Anterior restorations: The performance of ceramic veneers. Quintessence Int. 2018;49(2):89-101. doi: 10.3290/j.qi.a39509.

8. Peumans M, De Munck J, Fieuws S, Lambrechts P,Vanherle G, Van Meerbeek B. A prospective ten-year clinical trial of porcelain veneers. J Adhes Dent. 2004 Spring;6(1):65-76.

9. VazEC, Vaz MM, de TorresÉM, de Souza JB, Barata TJE, Lopes LG. Resin Cement: Correspondence with Try-In Paste and Influence on the Immediate Final Color of Veneers. JProsthodont. 2018 Jan 3. doi: 10.1111/jopr.12728. [Epub ahead of print]

10. Faus-Matoses V,Faus-Matoses I, Jorques-Zafrilla A, Faus-Llácer VJ. Orthodontics and veneers to restore the anterior guidance. A minimally invasive approach. J Clin Exp Dent. 2017 Nov 1;9(11):e1375-e1378. doi: 10.4317/ jced.54358. eCollection 2017 Nov.

11. Della Bona A. Bonding to ceramics: Scientific evidences for clinical dentistry. São Paulo: Artes Médicas:2009.252p.

12. Celik N, Yapar MI, Ta pınar N, Seven N. The Effect of Polymerization and Preparation Techniques on the Microleakage of Composite Laminate Veneers. Contemp Clin Dent. 2017 Jul-Sep;8(3):400-4. doi:10.4103/ccd.ccd_46_17.

13. Olley RC,Andiappan M, FrostP.An up to 50-year follow-up of crown and veneer survival in a dental practice. J Prosthet Dent. 2018 Jun;119(6):935-41. doi: 10.1016/.jprosdent.2017.06.009. Epub2017 Sep 29.

14. Schmitter M, Seydler B. Minimally invasive lithium disilicate ceramic veneers fabricated using chairside CAD/CAM: a clinical report. J Prosthet Dent. 2012 Feb;107(2):71-4. doi: 10.1016/S0022-3913(12)00012-1

15. Silva LHD, LimaE, Miranda RBP,Favero SS, Lohbauer U,Cesar PF.Dental ceramics: a review of new materials and processing methods. Braz Oral Res. 2017 Aug 28;31(suppl 1):e58. doi: 10.1590/1807-3107BOR-2017.vol31.0058.

16. Chai SY,Bennani V, Aarts JM, Lyons K. Incisal preparation design for ceramic veneers: A critical review. J Am Dent Assoc. 2018 Jan;149(1):25-37. doi:10.1016/j. adaj.2017.08.031.

\section{Janaina Emanuela Damasceno (Corresponding address)}

Piracicaba Dental School, University of Campinas, Av. Limeira, 901, P.O. BOX 52 Piracicaba, SP, Brazil, CEP 13414-903

E-mail: janaina.damasceno.santos@gmail.com

Date submitted: 2018 Jul 26 Accept submission: 2018 Sep 18 